\title{
Scheduling of Diesel Generators Operation with Restricted PCC in Microgrid
}

\author{
Nabil Jalil Aklo ${ }^{* 1,2}$, Mofeed Turky Rashid ${ }^{1}$ \\ ${ }^{1}$ Electrical Engineering Department, University of Basrah, Basrah, Iraq \\ ${ }^{2}$ Electrical Engineering Department, University of Thi-Qar, Thi-Qar, Iraq
}

\begin{abstract}
Correspondence
* Nabil Jalil Aklo

Electrical Engineering Department,

University of Thi-Qar, Thi-Qar, Iraq

Email: nabilj.aklo@gmail.com
\end{abstract}

\begin{abstract}
Smart Microgrid (MG) effectively contributes to supporting the electrical power systems as a whole and reducing the burden on the utility grid by the use of unconventional energy generation resources, in addition to backup Diesel Generators (DGs) for reliability increasing. In this paper, potential had been done on day-ahead scheduling of diesel generators and reducing the energy cost reached to the consumers side to side with renewable energy resources, where economical energy and cost-effective MG has been used based on optimization agent called Energy Management System (EMS). Improved Particle Swarm Optimization (IPSO) technique has been used as an optimization method to reduce fuel consumption and obtain the lowest energy cost as well as achieving the best performance to the energy system. Three scenarios are adopted to prove the efficiency of the proposed method. The first scenario uses a 24 hour time horizon to investigate the performance of the model, the second scenario uses two DGs and the third scenario depends on a 48-hour time horizon to validating the performance. The superiority of the proposed method is illustrated by comparing it with PSO and simulation results show using the proposed method can reducing the fuel demand and the energy cost by satisfying the user's preference.
\end{abstract}

KEYWORDS: Diesel Generators (DGs), Fuel consumption, Energy Management System (EMS), Improved Particle Swarm Optimization (IPSO), Renewable Energy Resources (RER).

\section{NOMENCLATURE}

$C_{t}^{D G} \quad$ Energy cost of DG at time slot t

$C^{\text {deg }} \quad$ Battery degradation cost

$C_{t}^{g} \quad$ Energy cost of the grid at time slot $\mathrm{t}$

$E_{b a t, \max }$ Maximum capacity of ESS

ES Energy charged to the battery

$E_{t} \quad$ Energy stored in ESS at time slot t

$F_{t} \quad$ Fuel amount consumed at time slot $\mathrm{t}$

$G_{t} \quad$ Forecast irradiance at time slot t

$G_{\text {stc }} \quad$ Test of standard condition irradiance

$k_{c} \quad$ Relative temperature coefficient

$P_{t}^{c h} \quad$ Rated power charged to ESS at time slot $\mathrm{t}$

$P_{t}^{c h, \max }$ Maximum rated power charged to ESS at time slot $\mathrm{t}$

$P_{t}^{\text {dis }} \quad$ Rated power discharged from ESS at time slot $\mathrm{t}$

$P_{t}^{d i s, \max }$ Maximum rated power discharged from ESS at time slot $\mathrm{t}$

$P_{t}^{D G} \quad$ Power generated from DG at time slot $\mathrm{t}$

$\begin{array}{cl}P^{D G, \text { min }} & \text { Minimum power allowed from DG } \\ P_{t}^{g} & \text { power generated from the grid at time slot } \mathrm{t} \\ P_{t}^{\text {pv }} & \text { PV power generated at time slot } \mathrm{t} \\ P_{P V}^{\text {max }} & \text { PV system rating } \\ P^{P C C} & \text { Maximum allowed power from PCC } \\ P^{D G, \text { rated }} & \text { Rated power of DG } \\ P_{t}^{\text {dis,load }} & \text { Power flow from ESS to the user at time slot } \mathrm{t} \\ P_{t}^{D G, c h} & \text { Charged power from DG to ESS at time slot } \mathrm{t} \\ P_{t}^{D G, \text { grid }} & \text { Power flow from DG to the grid at time slot } \mathrm{t} \\ P_{t}^{D G, l o a d} & \text { Power flow from DG to the users at time slot } \mathrm{t} \\ P_{t}^{\text {grid,ch }} & \text { Power flow from the grid to ESS at time slot } \mathrm{t} \\ P_{t}^{\text {grid,load }} & \text { Power flow from the grid to the users at time } \\ P_{t}^{\text {pv,ch }} & \text { slot } \mathrm{P} \\ P_{t}^{\text {pv,grid }} & \text { Power flow from PV to ESS at time slot } \mathrm{t} \\ P_{t}^{\text {pv,load }} & \text { Power flow from PV to the grid at time slot } \mathrm{t} \\ P_{t}^{\text {dis,grid }} & \text { Power flow from PV to the users at time slot } \mathrm{t} \\ P D G & \text { DG Power output }\end{array}$




$\begin{array}{cl}P g & \text { Power purchase or sold from/to the grid } \\ S O C^{t} & \text { State of charge at time slot } \mathrm{t} \\ \text { SOC }^{\text {max }} & \text { Maximum energy ratio saved in the battery } \\ \text { SOC }^{\text {min }} & \text { Minimum energy ratio saved in the battery } \\ T & \text { Time horizon } \\ T_{c} & \text { PV cell temperature } \\ T_{t} & \text { Ambient temperature forecast at time slot } \mathrm{t} \\ T_{n o c} & \text { Nominal operating cell temperature } \\ u_{t}^{c h} & \begin{array}{l}\text { Logic variable to control the battery charging } \\ \text { at time slot } \mathrm{t}\end{array} \\ u_{t}^{\text {dis }} & \begin{array}{l}\text { Logic variable to control the battery } \\ \text { discharging at time slot } \mathrm{t}\end{array} \\ x^{n} & \begin{array}{l}\text { Factor of imposing a penalty for exceeding } \mathrm{n}^{\mathrm{th}} \\ \text { constraint }\end{array} \\ z_{t} & \begin{array}{l}\text { Logic variable to control DG operation at time } \\ \text { slot } \mathrm{t}\end{array} \\ \alpha_{D G} & \begin{array}{l}\text { Coefficients represent incline of fuel } \\ \text { consumption curve of DG }\end{array} \\ \beta_{D G} & \begin{array}{l}\text { Coefficients represent interception of fuel } \\ \text { consumption curve of DG }\end{array} \\ \rho^{\text {deg }} & \text { Battery degradation factor } \\ \eta^{c h} & \text { Efficiency of charging power } \\ \eta^{d i s} & \text { Efficiency of discharging power }\end{array}$

\section{INTRODUCTION}

The flexible architecture and large penetration of Renewable Energy Resources (RER) in Micro-grid (MG) encourage the adoption of these networks with a variety of operation and management strategies that differ from those of the conventional systems [1]. An MG is defined as a distribution, controllable, and low voltage network connected/disconnected with the utility grid at Point of Common Coupling (PCC) comprising RER and/or nonRER, Energy Storage Systems (ESS), and responsive loads. MG can be set up in both two modes, grid-connected or islanded modes [2]. The power can be traded off between the utility grid and MG through PCC by importing and exporting under different energy tariffs. MG can also provide additional services like voltage support and regulation to the utility grid that a conventional end-user system cannot support [3]. From the users' point of view, MG regards as a cheap energy resource by the presence of RER and ESS, also participate in decreasing emissions due to reducing the fossil fuel energy resources dependence. Moreover, it can enhance the power quality by regulating the voltage and reducing its dips [4], [5], [6].The diversity of energy resources in the MG make it more secure, more economic, and sustainable than that relying on a unique technology resource, but the process of coordinating energy resources throughputs become complex and this issue is considered a challenge for energy control systems designers due to their differences in mechanics, response, and efficiencies [7]. The presence of RERs in the MG impacts the system operation, where the probabilistic nature of weather conditions like wind speed and sun irradiance make RERs power significantly fluctuate continuously. In addition to that, the hourly load behavior and energy price change from time to time greatly increase the complexity of the system modeling and controlling [8]. Usually, the MGs are installed in remote, rural, isolated areas or regions that are equipped with a limited level of electrical energy from the utility grid in addition to the uncertainty problems of several parameters and variables and other reasons associated with the unreliability of the supplying of RER, all these reasons lead to insufficient energy supplying and unreliability of its continuation.

To enhance the MG operation and overcome the uncertainty problem of RER power generation and increase the reliability, the Diesel Generators (DGs) are incorporated in the MG. The DG is a reliable, dispatchable energy resource used to cover energy demand in times of power generation shortages or during times of high demand in order to prevent the load shedding and avoiding of customers preference effecting. Despite the intended benefit of the generator, the energy generated from it is considered expensive and costly due to its dependence on expensive fuel in addition to other factors such as maintenance, operating hours, starting up/ shutdown of operation.

To exactly benefit from the DG and obtain energy at the lowest cost, scheduling of the DG operation with other energy resources such as PV must be made using EMS by specifying the hours of commitment and allocation of the diverse energy sources taking into account the effecting of other variables such as energy tariff, demand load... etc., thus the fuel consumption used is scheduled.

For the sustainability of the generator's work and its readiness for use at all times especially during peak and emergency times, there must be a permanent abundance of fuel in the fuel tanks, and this requires scheduling the use and purchasing fuel from suppliers. One of the methods of supplying and ensuring the availability of fuel for generators is the take or pay method. Take or pay method states that providing the fuel to the buyer by fixed quantities during periodic intervals of time determined between the supplier and the consumer according to an agreement signed between them, and this imposes on the users to consume all the supplied fuel within the specified time horizon in order to avoid the penalties and financial payments stipulated in the agreement or the accumulation of fuel otherwise, but this strategy is considered costly and useless, thus causes additional burdens on the operation of EMS whose main goal is to reduce the cost of energy generation in an optimal way.

Significant efforts have been devoted in the field of the MG resources scheduling operations over the past years, as scheduling processes are divided into two parts, one part is related to scheduling the work of energy sources and the other part is related to fuel disbursement schedule.

Scheduling the operation of energy resources of all kinds has taken a large space of scientific research. In [9], a dynamic optimal schedule technique for the MG in two modes, isolated and connected modes are proposed depending on dynamic programming and equal $\lambda$-algorithm to solve economic load dispatching problem for EMS so as to minimize the cost of fuel which is used in a micro-turbine generators and to maximize the profit of the MG in the connected mode, however, this paper did not discuss the constraints of energy at PCC and restrict the customers 
preferences, the same matter in the paper [10] and [11] where in [10] it is introduced a decentralized dispatch of power model and Distribution Network Operator (DNO) to coordinating the operation of multiple MGs by minimizing their operation costs while in [11] day-ahead scheduling of stochastic system in energy markets is proposed, this paper is present a chance-constrained stochastic programming the method with economic metrics to increase the reliability and obtain energy at a lowest cost from the energy market but without taking into account the PCC limitations.

In [12] EMS of MG based on a rolling horizon method and mixed integer optimization is proposed. The control process of this work does not take into account the uncertainty of the system parameters unlike paper [13] in which the EMS takes a two-day-ahead forecast of RER and a two-day-ahead estimation for energy consumption depending on a neural network.

In [14] day-ahead scheduling is presented for energy hubs with the aid of the Monte-Carlo method for scenario generation and fast forward selection way. The mathematical model is divided into two parts, first part represents the energy hub modeling with entire its energy resources and constraints while the second part is demand-side modeling, inelastic and elastic loads are isolated from the energy demand in order to properly use the shiftable/shavable features of the elastic loads, but this research restricts the user preferences in order to reduce peak demand without suggesting alternatives of generation, this problem treated in paper [15] that deals with the economic optimal operation problem of CHP by using chance-constrained programming to cover the randomness of RERs and other factors, but not cover the issue of fuel supply in order to ensure reliability.

Reference [16] introduces a model that calculates the power system reliability by utilizing multi-scenario approaches to long-term unit commitment. The main constraint of the model is the loss-of-load-expectation (LOLE) to calculate the cost of the power supplying in the system. The disadvantage of this research is the lack of reliance on the short-term in calculating the cost of energy also The same matter in [17] and [18] that they use a stochastic constrained model in long-term, using multiscenario analyses by regarding generating resources and power failure in addition to load forecast errors but in [18] it is used a high wind penetration.

The second part of the literature review is concerned with scheduling fuel of DGs. In [19] is proposed a practical adaptive method using pseudo fuel prices for fuel allocation and generator dispatching, however, the shortcoming of this research is the lack of dependence on realistic data in realtime, while reference [20] presents the Lagrangian Relaxation approach for short term unit commitment optimization and scheduling in system consist of three types of generation units: fuel constrained, thermal and hydro also several techniques employed to analyze the unit commitment issue, one depend on Priority Lists Scheme in reference [21], other use Dynamic Programming that in [22] and lastly Mixed Integer Programming is used in [23] but all these papers did not tackle the problem of uncertainty of main variables such as PV generation, energy price or nature of habitants habits.
The cost minimization approach for an $\mathrm{MG}$ is presented in [24], it is a short-term optimization of stochastic model in rural $\mathrm{MG}$, which is proposed to minimize the fuel consumption and $\mathrm{CO}_{2}$ emission, at the same time improving the system quality and enabling activities of generating the community using Monte Carlo as an optimization methodology in order to deal with uncertainties in RER production and loads, but this work did not address the guarantee of fuel availability in the peak times.

In this paper, a short-term and medium term optimization mechanism is proposed for PV-battery-diesel hybrid MG in the rural areas to supplying the fuel along the time horizon while EMS is presented to reduce fuel consumption, emission, and supplying energy to the end-user at the lowest cost. A day-ahead scheduling model and Improved Particle Swarm Optimization (IPSO) algorithm are introduced to achieve the objectives of the proposed system.

Three scenarios have been proposed to validate the model's performance. The first scenario uses a 24 hour time horizon to investigate the performance of the model, the second scenario uses two DGs instead of one in the first, and the third scenario depends on 48-hour time horizon.

According to the literature review, the essential contributions of this work are:

- A proposed model has been introduced for fuel supplying and consumption, which can cope with RER and other variables uncertainties in the MG based on scheduling fuel consumption. The MG includes RER, ESS, the limited power of the grid at PCC, and EMS.

- EMS employs IPSO as an optimization strategy to compute optimum day-ahead scheduling for RER and DG operation to find the lowest energy cost for the benefit of the end-users. The results of IPSO are compared with these obtained using PSO to show its superiority.

- Life extending of ESS by regulating charging/discharging in optimization process that depending on the load demand, the energy tariff, and RER generation, taking into account the times of charging and discharging along time horizon which leading to battery degradation life.

- The case study that had been worked on is real data of two typical days in July, wherein this month the demand is high and the generation of PV is large also the energy tariff is disparate, thus these reasons make the EMS work in an obvious manner.

- Three scenarios have been proposed depending on the time horizon and number of DG to validate the proposed system and evaluate the performance of the EMS.

The remainder of this paper is structured as follows: Section II discusses the system architecture and formulation of control system also principles of Improved Particle Swarm Optimization. Section III describes the mathematical modeling and methodology and the objective function. Section IV presents and discusses the results, finally, the conclusion is summarized in section $\mathrm{V}$. 


\section{Problem Formulation}

\section{A. System Architecture}

Figure 1 shows the system architecture, it consists of MG connected directly to the utility grid at PCC, the MG contains PV panels, ESS, DG, and residential loads. The MG has an EMS for power flow management between the MG components. The power flow between household loads and energy resources are in one direction and between the grid and MG resources in two directions (buying and selling) between the grid and MG, PV, ESS, and DG are owned by the government. The main purpose of ESS is to decrease energy cost and enhance reliability. The MG resources can supply the power to the users in order to prevent household load shedding and avoid their preferences affecting [25]. The EMS goal is to minimize the cost of energy by decreasing fuel consumption along the time horizon. The controller takes the optimal decisions and the amount of power is decided to be traded with the utility grid taking into account the limits of PCC and the constraints related to RERs and DG limits.

The operation of EMS has been optimized by IPSO to meet the optimum operation of supplying electrical power to the customers in MG. The details of the optimization model are in the next sections.

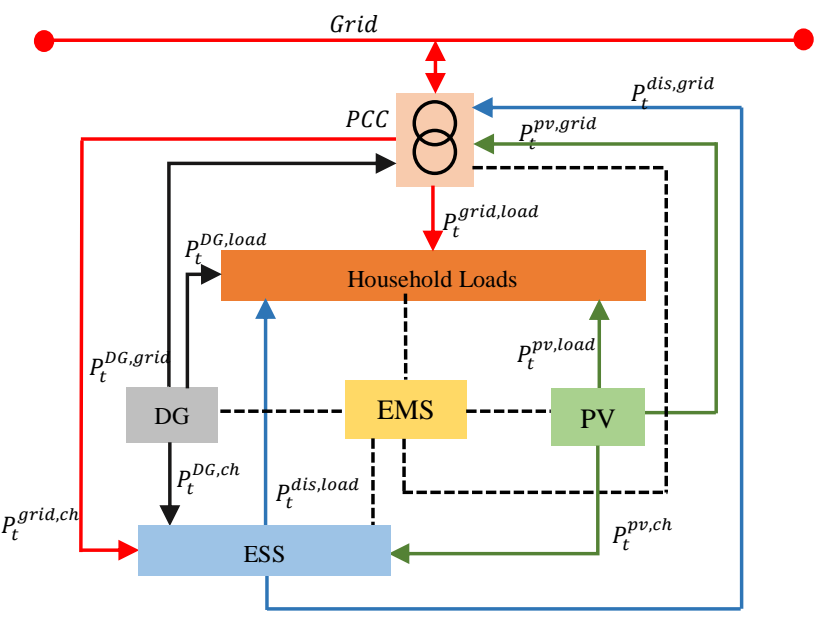

Fig. 1 MG Architecture.

\section{B. Improved Particle Swarm Optimization (IPSO).}

Among the optimization technologies, Particle Swarm Optimization (PSO) has been used for the proposed EMS due to its high convergence speed, robustness, and simplicity. PSO is a model-based and evolutionary computation method algorithm to find the optimum solution, it uses swarm intelligence to find the solution. This technique was developed by imitating a flock of birds flying within any region looking for food. PSO explores to find the objective by doing a population-based random search [26]. The populations include potential solutions named particles, which are an image of birds in flocks. These particles are initialized randomly and fly freely through the multidirectional search space. During the flight, the particles update their velocity and position depending on the best experience of each particle and all populations encountered on the current journey.
As a result of the updating, the particle swarm will be steered toward the more promising region that has a high objective value, then more and more particles will be collected near the optimum point [27-28]. The equations below illustrate the mathematical concept of the principle explained above.

$$
\begin{gathered}
V_{j}(i)=V_{j}(i-1)+c_{1} r_{1}\left[P_{b e s t, j}-X_{j}(i-1)\right] \\
+c_{2} r_{2}\left[G_{b e s t}-X_{j}(i-1)\right] ; j=1,2, \ldots, N \\
X_{j}(i)=X_{j}(i-1)+V_{j}(i) ; j=1,2, \ldots, N
\end{gathered}
$$

Equation (1) represents the jth particle velocity in the ith iteration, while (2) indicates the position of the $j$ th particle in $i$ th iteration, where $\mathrm{c} 1$ is the individual learning rates and $\mathrm{c} 2$ is social learning rates, while $\mathrm{r} 1$ and $\mathrm{r} 2$ are the distributed random numbers specified between 0 and 1 . $\mathrm{N}$ refers to the number of particles and Pbestj is the best historical value of $x j(i)$ that has the largest objective function in the current iteration. Gbest is the best historical value of all particles from past until current iteration that has the largest objective function value in all previous iterations.

The velocities of particles in PSO are accumulated rapidly and this leads to jumping to the maximum point of the objective function. To overcome this problem a factor is added to decelerate the velocity of the particle and enabling it to converge more efficiently, this factor is called the inertia term, $w$, and traditional PSO becomes IPSO. The value of, w, is usually confined between 0.4 and 0.9 during the iteration progresses. The $j$ th modified particle velocity is demonstrated as:

$$
\begin{aligned}
V_{j}(i)= & w V_{j}(i-1)+c_{1} r_{1}\left[P_{\text {best }, j}-X_{j}(i-1)\right] \\
& +c_{2} r_{2}\left[G_{\text {best }}-X_{j}(i-1)\right] ; j=1,2, \ldots, N
\end{aligned}
$$

Equation (3) shows a higher value of,w, support global point and a lower value support a local point. Thus a maximum value of $w$ leads to makes PSO seek new regions taking into account no much local optima, thus leads to failure in finding the true optimum point. A proposed solution to this problem is by making balance between the two local and global optima, this achieved by make, $w$, decrease by a linear relation with the iteration number as seen in (4) [29]:

$$
w(i)=w_{\max }-\left(\frac{w_{\max }-w_{\min }}{i_{\max }}\right) i
$$

$w_{\max }$ and $w_{\min }$ is the maximum and minimum value of inertia weights respectively, $i_{\max }$ is the maximum iteration number used in the algorithm.

\section{Mathematical Modeling And Problem FORMULATION}

\section{A. Mathematical modeling of system components}

EMS accepts the data from all components and PCC to obtain grid energy price and the capacity of lines information. The MG is placed in the connected mode, while the objective function goal is to minimize the entire operation cost associated with the energy cost of buying/selling power from/to the grid, fuel consumption and 
cost, battery degradation cost, and cost/benefit of purchasing/selling power from/to the utility grid, as shown in (5), (6) and (7).

$$
\begin{array}{cc}
\min \sum_{t \in T} C_{t}^{g}\left(P_{t}^{g}\right)+C^{D G}\left(P_{t}^{D G}\right)+C^{d e g} \quad \forall t \in T \\
C^{D G}=\left(\frac{F * C^{f}}{P_{t}^{D G}}\right)+M c & \forall t \in T \\
C^{d e g}=\rho^{d e g}\left(\left|S O C_{t}-S O C_{t-1}\right|\right) & \forall t \in T
\end{array}
$$

The cost of trading off power between the utility grid and MG at time slot $t$ is represented in the first term of the objective function (5), where the tariff of power changes from slot to slot at PCC, the second term in (5) is the DG power cost at each time slot $t$, the DG power cost relying on fuel price and maintenance cost as shown in (6), it also depends on the dispatched power from the DG, where at the high generation the price becomes lower, while the third term in (5) is the cost of ESS degradation due to frequent charging or discharging process as seen in (7) where the change between the two battery processes leads to life degradation [30].

The main goal of this work that must be performed is to minimize the overall cost of the energy at each time slot by increase the relying on RERs and decreasing the DG operation as possible. For this objective, the variables of optimization (Decisions) are become battery charging/discharging orders and the DG operations order. EMS uses IPSO to dispatching the operation of resources to meet load requirements and fuel consuming minimize. The mathematical modeling of the MG is divided into four parts as demonstrated below.

\section{1) Photovoltaic panels}

The power generated using the PV panels based on environmental and structural factors like the irradiance intensity, $\mathrm{PV}$ panel temperature $\mathrm{T}_{\mathrm{c}}$ or ambient temperature as shown in (8) and (9) [31]:

$$
T_{c}=T_{t}+\frac{G_{t}}{800}\left(T_{n o c}-20\right) \quad \forall t \in T
$$

where $\mathrm{T}_{\text {noc }}$ is the nominal cell temperature. The PV generation can then be computed in (9):

$$
P_{t}^{p v}=\frac{G(t)}{G_{s t c}} P_{P V}^{\max }\left(1+k_{c}\left(T_{c}-T_{s t c}\right) \eta_{M P P} \forall t \in T\right.
$$

$\mathrm{G}(\mathrm{t})$ : forecast irradiance, $\mathrm{G}_{\mathrm{stc}}$ : standard test condition irradiance, $\mathrm{k}_{\mathrm{c}}$ : relative temperature coefficient.

\section{2) ESS model}

The main purpose of using the ESS system is to store the excess energy from RERs and other resources and thus compensate for the energy shortage during periods of lack of supplying power to the load. The ESS is modeled as (10) [32], [33]:

$$
\begin{aligned}
E_{t} & =E_{t}+\Delta T * P_{t}^{c h} * \eta^{c h} * u_{t}^{c h}-\frac{\Delta T \times P_{t}^{d i s}}{\eta^{d i s}} * \\
u_{t}^{d i s} & \forall t \in T
\end{aligned}
$$

Where $\mathrm{u}_{\mathrm{t}}{ }^{\text {ch }}$ and $\mathrm{u}_{\mathrm{t}}{ }^{\text {dis }}$ are a variables to control battery charging/discharging, as derived in (11) and (12).

$$
\begin{array}{lc}
u_{t}^{c h}=-\operatorname{action} 1 *(1-\operatorname{action} 1) / 2 & \forall t \in T \\
u_{t}^{\text {dis }}=\operatorname{action} 1 *(1+\operatorname{action} 1) / 2 & \forall t \in T
\end{array}
$$

The ratio between the instantaneous capacity of ESS bank and overall capacity is named State of Charge (SOC), it regards from an essential variable that must be controlled, and it represents the time slot energy of the battery and its mathematical modeling shown in (13).

$$
S O C=\frac{E_{t}}{E_{\text {bat }, \text { max }}} \quad \forall t \in T
$$

\section{3) Diesel Generator model}

The goal of the DG is to supply the necessary energy demand when the RER cannot meet the load demand. The fuel consumption at each time slot is based on the dispatched power from the generator and rated power, the mathematical model is shown in (14):

$$
F_{t}=\alpha_{D G} * P_{t}^{D G}+\beta_{D G} * P^{D G, \text { rated }} \quad \forall t \in T
$$

$\alpha_{D G}$ and $\beta_{D G}$ are factor represent the incline and interception of the fuel consumption curve, its typical values equal are $0.2461 / \mathrm{KWh}$ and $0.8151 / \mathrm{KWh}$ respectively [3436].

\section{4) Utility grid}

In this work, the power flow through the PCC point from the utility grid to $\mathrm{MG}$ is appointed within a certain limit as a result of the scarcity of energy supplied to remote areas. PCC is a power switch that is used to jointing the MG system to the main grid.

\section{B. System components constraints}

The constraints related to the controller of the system are listed in below:

- Power balance constraints.

- Energy capacity constraints.

- Operational constraints.

The power balance constraint is the algebraic sum of generated power from all MG resources [37]. The balance equation of generation and consumption is shown in (15).

$$
P_{t}^{L}-P_{t}^{g}-P_{t}^{p v}-P_{t}^{D G}-P_{t}^{d i s}+P_{t}^{c h}=0 \quad \forall t \in T
$$

$\mathrm{P}_{\mathrm{t}} \mathrm{g}^{\mathrm{g}}$ is the utility grid power, the positive sign means buying power from the utility grid and negative sign means selling while zero means no power trading off.

The PCC constraint included in (16) shows the upper limit of allowed power that must not exceed across PCC.

$$
P_{t}^{g} \leq P^{P C C} \quad \forall t \in T
$$

The DG constraints are depicted in (17) and (18). Equation (17) illustrates the upper and lower bounds of the generated power output of $\mathrm{DG}, \mathrm{k}$ is set to 0.35 according to the manufacturers' instructions. Equation (18) is a logic variable that describes the status of DG operation.

$$
\begin{aligned}
& z_{t} \cdot k \cdot P^{D G, \text { rated }} \leq P_{t}^{D G} \leq z_{t} \cdot P_{t}^{D G, \text { rated }} \quad \forall t \in T \\
& \boldsymbol{z}_{\boldsymbol{t}}=\left\{\begin{array}{ll}
\mathbf{1} & \boldsymbol{D} \boldsymbol{G} \text { is on } \\
\mathbf{0} & D G \text { is off }
\end{array} \quad \forall \boldsymbol{t} \in \boldsymbol{T}\right.
\end{aligned}
$$

Constraints of ESS are listed in (19), (20), (21), and (22). (19) and (20) explain the maximum and minimum bounds of ESS rated power in both charging and discharging cases, (21) shows the allowable percentage ratio of ESS capacity limits, and (22) shows the control variables constraint in order to 
avoid charging/discharging at same time slot, its value ' 0 ' or ' 1 ' as seen in (23).

$$
\begin{array}{lc}
\mathbf{0} \leq \boldsymbol{P}_{t}^{c h} \leq \boldsymbol{u}_{t}^{c h} \cdot P_{t}^{c h, m a x} & \forall t \in T \\
\mathbf{0} \leq \boldsymbol{P}_{t}^{\text {dis }} \leq \boldsymbol{u}_{t}^{\text {dis }} . P_{t}^{\text {dis,max }} & \forall t \in T \\
\boldsymbol{S O C}^{\text {min }} \leq \boldsymbol{S O C}_{t} \leq \boldsymbol{S O C}^{\text {max }} & \forall t \in T \\
\mathbf{0} \leq \boldsymbol{u}_{t}^{\text {ch }}+\boldsymbol{u}_{t}^{\text {dis }} \leq \mathbf{1} & \forall t \in T \\
\boldsymbol{u}_{t}^{c h}, \boldsymbol{u}_{t}^{\text {dis }} \in\{0,1\} & \forall t \in T
\end{array}
$$

\section{SimULATION RESULtS AND ANALYSIS}

The simulation has been achieved on an MG consists of a PV array contain 300 panels, DG, and ESS. DG rated power is computed by consideration of the historical maximum load profile. ESS is connected to PCC, PV, and DG on the first side and the loads on the second side as demonstrated in Fig. 1, in which the surplus power of PV can be used to charge the ESS, moreover, the low-cost power of grid can inject into the ESS at optimal time slot, all of these charging processes based on balance equation (15). Table I shows the details of the parameters and variables of the proposed system.

In this paper, there are three scenarios have been adopted to validating the optimization method and check the performance based on three factors, time horizon factor, number of DG factor and DG rated power factor, these scenarios are:

1. Use 24 hour time horizon and one DG of $1000 \mathrm{KW}$ rated power.

2. Use 24 hour time horizon and two DGs each one of 500 $\mathrm{KW}$ rated power.

3. Use 48 hour time horizon and one DG of $1000 \mathrm{KW}$ rated power.

\section{A. First scenario}

A typical day of optimized data has been taken, the demand load, PV array energy generation, and energy tariff profiles of utility grid are described in Fig. 2, Fig. 3, and Fig. 4 , respectively. EMS has been optimized by IPSO, which the decided actions are shown in Fig. 5. From the actions, it is noted that the DG work at the minimum border that is constrained in (17), and charging actions occur at a time slot in which the energy tariff of the utility grid is cheap or when there is surplus DG power during working in the minimum boundary. The schedule of energy tradeoff between MG and the utility grid is shown in Fig. 6. The utility grid energy supplied to the MG is constrained by a specified limit at PCC, in this paper, it must not pass $1.5 \mathrm{MW}$. It is seen from the figure that the upper limit is reached nearly at peak times (11-23) hours and there is no power sold to the utility grid along the time horizon.

Figure 7 illustrates the SOC of ESS, it is noted that ESS is charged at the first hours of the day in which the energy tariff of utility grid is low while discharge in peak times of high energy tariff, at the same time, it is observed that there is no violation of the restrictions on the battery capacity, whether by charging or discharging, where the highest

\begin{tabular}{|c|c|c|c|c|}
\hline \multirow{4}{*}{ CBESS } & $\begin{array}{c}S O C^{\min } \\
(\%)\end{array}$ & $\begin{array}{c}S O C^{\max } \\
(\%)\end{array}$ & $\begin{array}{l}u_{t}^{c h, \max } \\
(\mathrm{KWh})\end{array}$ & $\begin{array}{l}\mathrm{u}_{\mathrm{t}}{ }^{\mathrm{dis}, \max } \\
(\mathrm{KWh})\end{array}$ \\
\hline & 20 & 90 & 250 & 250 \\
\hline & $\begin{array}{l}E^{\max } \\
(\mathrm{kw})\end{array}$ & $\begin{array}{l}\eta^{c h} \\
(\%)\end{array}$ & $\begin{array}{l}\eta^{\mathrm{dis}} \\
(\%)\end{array}$ & $\begin{array}{c}\rho^{d e g} \\
(\$ / \mathrm{MW})\end{array}$ \\
\hline & 2500 & 0.9 & 0.9 & 100 \\
\hline \multirow{4}{*}{ DG } & $\begin{array}{l}P^{D G, m i n_{t}}{ }_{t} \\
(\mathrm{KWh})\end{array}$ & $\begin{array}{l}P^{D G, \text { rated }}{ }_{t}{ } \\
(\mathrm{KWh})\end{array}$ & $\begin{array}{c}\alpha_{D G} \\
(1 / \mathrm{KWh})\end{array}$ & $\begin{array}{c}\beta_{D G} \\
(1 / K W)\end{array}$ \\
\hline & 350 & 1000 & 0.246 & 0.08145 \\
\hline & $\begin{array}{c}F^{\max } \\
\text { (Liter) }\end{array}$ & $\begin{array}{c}C^{f} \\
(\$ / 1)\end{array}$ & & \\
\hline & 2250 & 0.75 & & \\
\hline \multirow{4}{*}{ PV } & $\begin{array}{c}P^{\max }{ }_{P V} \\
(\mathrm{w})\end{array}$ & $\begin{array}{l}T_{\text {noc }} \\
\left(\mathrm{C}^{\mathrm{O}}\right) \\
\end{array}$ & $\begin{array}{c}G_{s t c} \\
\left(\mathrm{w} / \mathrm{m}^{2}\right)\end{array}$ & $\begin{array}{r}T_{\text {stc }} \\
\left(\mathrm{C}^{\mathrm{O}}\right) \\
\end{array}$ \\
\hline & 200 & 44.5 & 1000 & 25 \\
\hline & $\begin{array}{c}K_{c} \\
\left(\% / \mathrm{C}^{\circ}\right) \\
\end{array}$ & $\begin{array}{c}\eta_{M P P} \\
(\%) \\
\end{array}$ & & \\
\hline & 0.43 & 90 & & \\
\hline \multirow[t]{2}{*}{ PCC } & $\begin{array}{c}P^{P C C, \max } \\
(\mathrm{MW})\end{array}$ & & & \\
\hline & 1.5 & & & \\
\hline
\end{tabular}
percentage of filling the battery is $87 \%$ at time slot 14 and the lowest percentage is $20 \%$ at time slots 21,22 and 24 .

TABLE I

MG Parameters Details

The hourly cost of required energy along the time horizon is different from region to region depending on several factors, such as time of use, energy tariff, DG usage, or PV availability. Fig. 8 shows the hourly cost along the time horizon. From the figure, it is noted that the high energy cost appears in the time slots in which the DG is in the run state (slots 14, 16, 18, 19, 20, and 21 see Fig. 5).

This lead to make hourly energy cost high because the rest of the demand load in the time slots of the DG operation is lower than the minimum operation boundary of DG, for an instant, the need for energy from the generator at hour 14 is approximately $50 \mathrm{KW}$ (regarding PCC constraint), in such case, it is obliged to run the generator at the minimum generation limit $(350 \mathrm{KW})$, the same thing done on other slots.

In this case, the rest of the DG power is either used to supply the demand or to charge the ESS, thus the energy cost becomes high.

To overcome the effects of this problem and reduce the extra cost resulting from operating the DG at the minimum limit, it resorts to the second scenario which adopts the use of two generators.

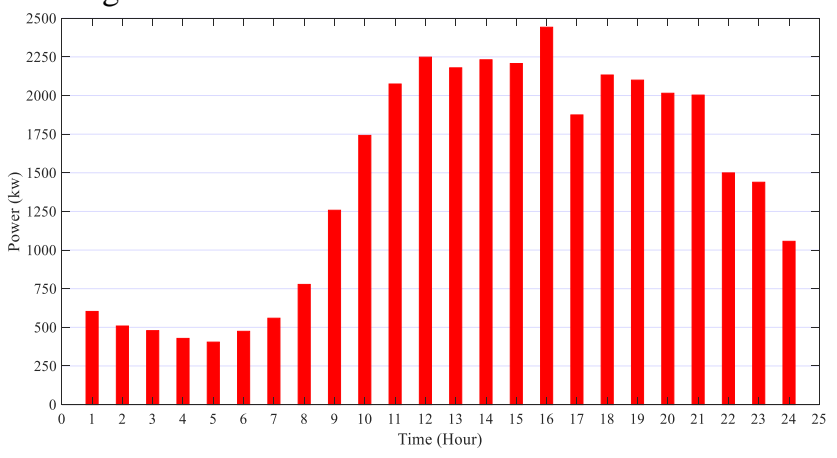

Fig. 2 Demand load profile. 


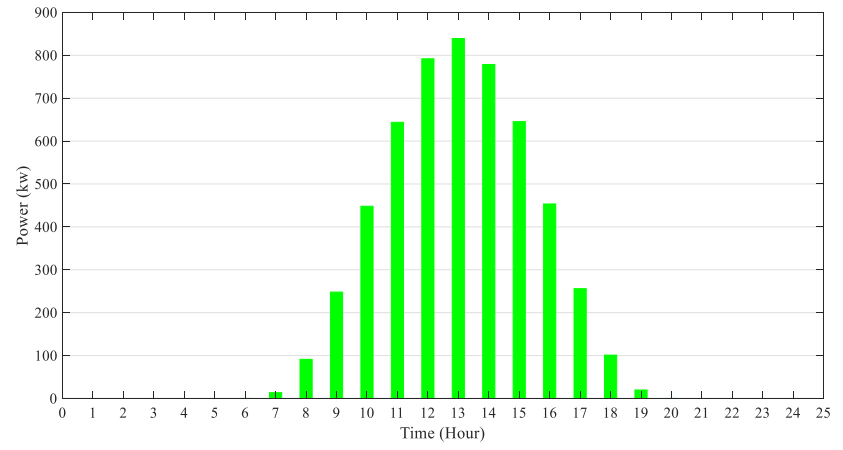

Fig. 3 PV generation profile.

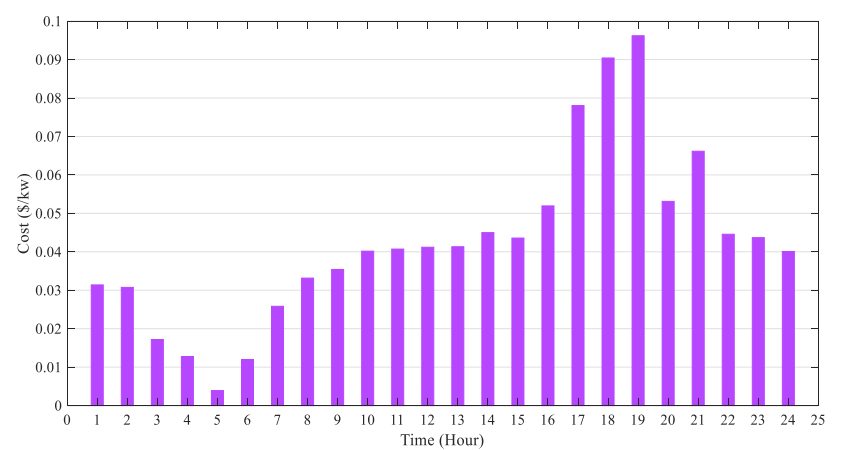

Fig. 4 Energy tariff profile.

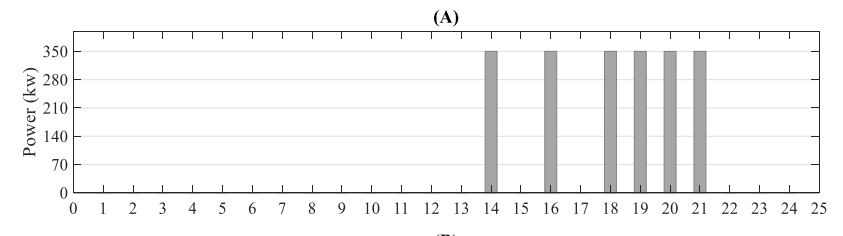

(B)

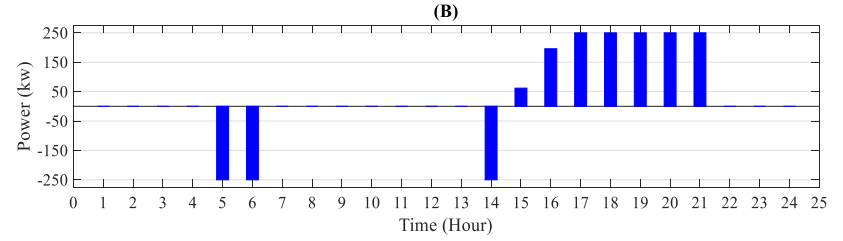

Fig. 5 EMS Actions. (A) is DG actions, (B) is ESS actions.

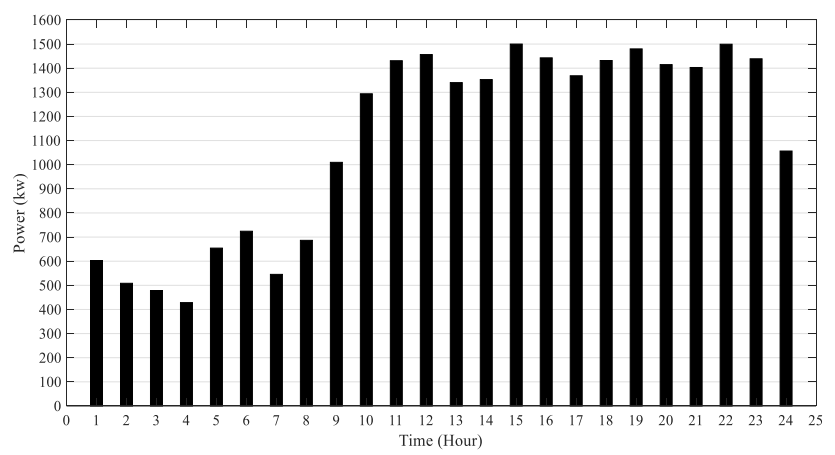

Fig. 6 Energy purchased from the utility grid.

Finally, the power balancing of this scenario is shown in Fig. 9, the negative sign of power in the curve represents the amount of charged energy to ESS from sources which pass the red curve (demand load), wherein the slot 5 and 6 , the battery is charged from the utility grid (black bar) and solar (green bar) while in slot 14 it is charged from solar only.

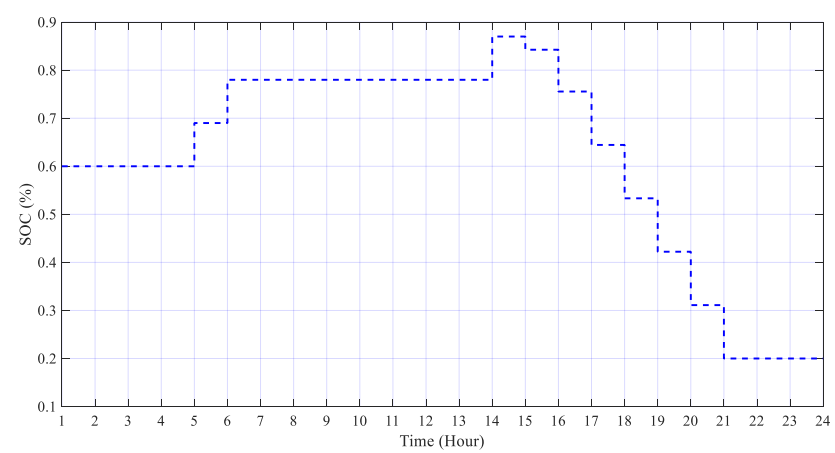

Fig. 7 State of charge in the ESS.

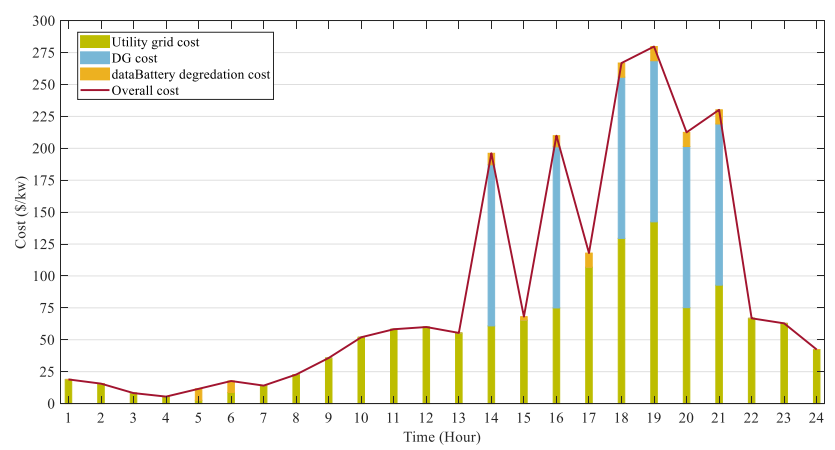

Fig. 8 Hourly cost of energy.

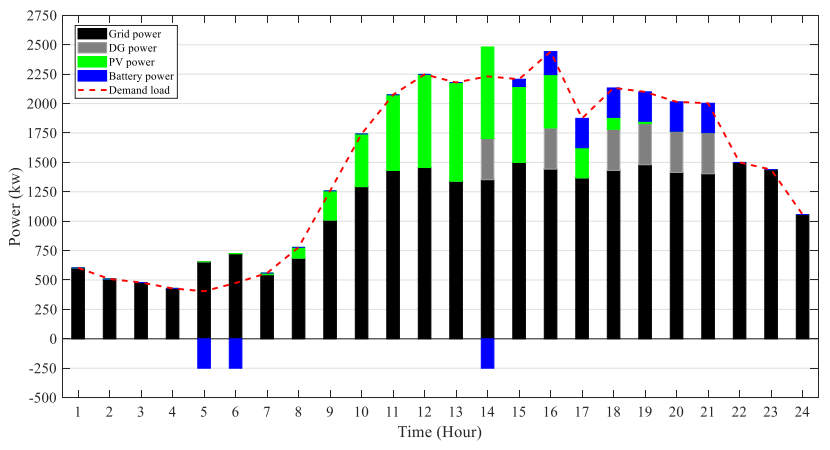

Fig. 9 The distribution of energy generation.

\section{B. Second Scenario}

In this scenario, the same parameters and variables have been used except the generator number. It is used two smaller generators with identical rated power equal to the half of rated power of the generator in the first scenario for each one $(500 \mathrm{KW})$.

The goal of this operation is to decrease fuel consumption as will be explained. EMS has been optimized by IPSO, and it will make the decision as shown in Fig. 10. In comparison with the decisions taken in the first scenario, it is noted that there is a difference in the generating capacity of the DGs, as it is observed that the operating capacity of the DG in the second scenario is $1525 \mathrm{KW}$, while $2100 \mathrm{KW}$ in the first scenario with a difference of $575 \mathrm{KW}$, therefore it is clear from the decisions of the second scenario not to run the second DG. 
As compared with the first scenario, it is noted that the need at the same time slot requires drawing a small capacity from the DG and this requires operating the DGs in both scenarios at the minimum limit, but in the first scenario the minimum limit is greater than the minimum limit in the second scenario, Here, the difference tends to favor the second scenario and therefore we do not need to operate the second DG.As a result of this operation, the fuel consumed in the first scenario is $1005 \mathrm{~L}$ and $624 \mathrm{~L}$ in the second scenario with a difference of $381 \mathrm{~L}$ and thus the average energy cost per hour in the second scenario becomes less than in the second scenario.

Fig.11 illustrates the comparison between the two scenarios in term of energy cost. Table II shows the ratio error of the factors in the two scenarios. Figure 12 shows the hourly cost of power that purchased from the utility grid for the two scenarios, which there is a cost juxtaposition in the two scenarios.

(A)
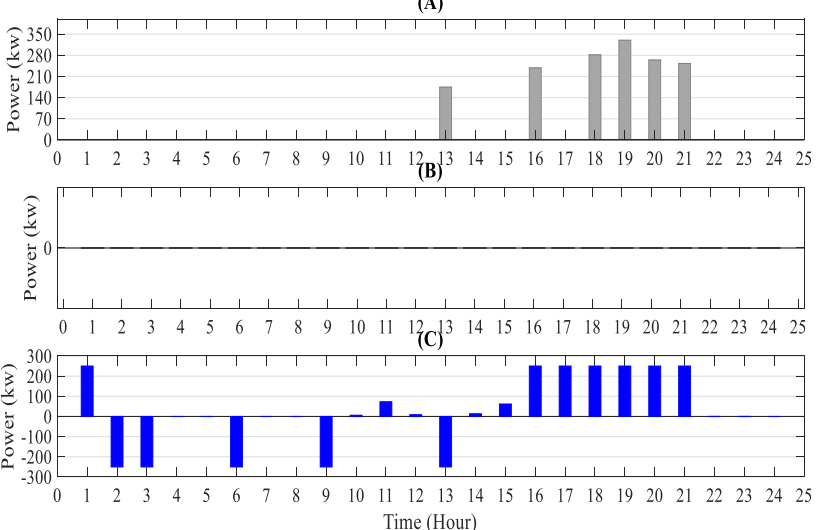

Fig. 10 EMS Actions. (A) DG1 actions, (B) DG2 actions (C) ESS actions.

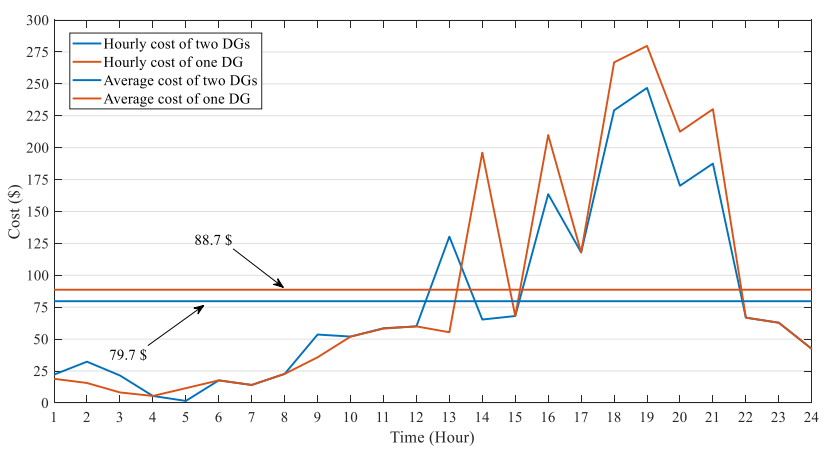

Fig. 11 Hourly energy cost of the two scenarios.

TABLE II

Comparison between first and second scenarios.

\begin{tabular}{ccc|c}
\hline \hline Comparison factor & $\begin{array}{c}\text { First } \\
\text { scenario }\end{array}$ & $\begin{array}{c}\text { Second } \\
\text { scenario }\end{array}$ & $\begin{array}{c}\text { Error } \\
(\%)\end{array}$ \\
\hline $\begin{array}{c}\text { Fuel consumption } \\
(\mathrm{L})\end{array}$ & 1005 & 624 & $37.6 \%$ \\
\hline $\begin{array}{c}\text { Daily cost } \\
(\$)\end{array}$ & 2129 & 1912 & $10.2 \%$ \\
\hline $\begin{array}{c}\text { Hourly cost } \\
(\$)\end{array}$ & 88.7 & 79.7 & $10.15 \%$ \\
\hline
\end{tabular}

Fig. 13 shows the cost of energy drawn from the generators, it is noted that there is a clear difference in the cost of the two scenarios because the cost in the second scenario is much lower than in the first scenario due to the use of small-sized generators.

Table III illustrates the details of the energy cost for the DGs and utility grid in the two scenarios according (5).

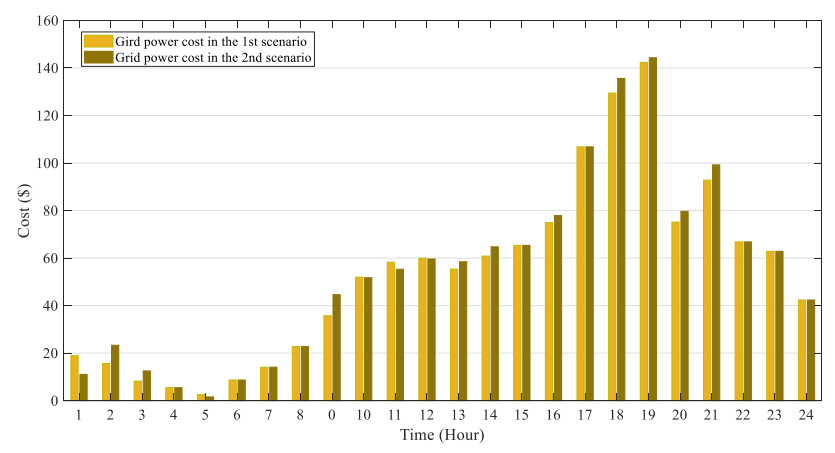

Fig. 12 Hourly cost of utility grid in the two scenarios.

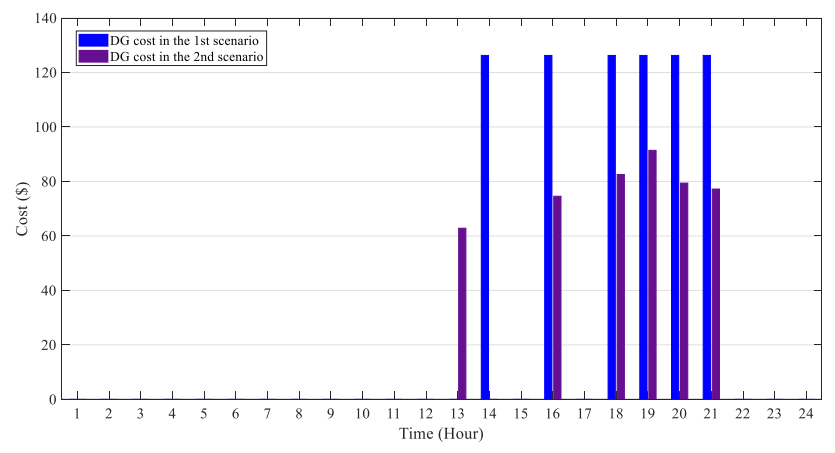

Fig. 13 Hourly cost of DGs in the two scenarios.

TABLE III

Average Hourly Cost in the Two Scenarios (\$)

\begin{tabular}{ccc|c}
\hline \hline Energy source & $\begin{array}{c}1 \text { st } \\
\text { scenario }\end{array}$ & $\begin{array}{c}2^{\text {nd }} \\
\text { scenario }\end{array}$ & Error \\
\hline Utility grid & 53.22 & 54.8 & 1.6 \\
\hline DG & 31.56 & 19.5 & 12 \\
\hline Battery degradation & 3.92 & 5.4 & 1.5 \\
\hline Total & 88.7 & 79.7 & 9 \\
\hline \hline
\end{tabular}

\section{Third Scenario}

In this scenario, the data of two days has been used as shown in Fig. 14, Fig. 15, and Fig. 16 that represent load, solar power, and energy tariff, respectively. In the case of optimizing the EMS by IPSO, the decisions of the DG running are made as shown in Fig. 17(A).

Fig. 17(B) shows DG decisions of the two days when they optimized separately (24-hour time horizon). It can be concluded from the case of running the DG in the two horizons that EMS running the DG many times with a more percentage of operation in the 48 -hour time horizon than in 
the 24 hour time horizon, where the total operating hours in the long time horizon amounted to 15 hours with a total generation of $7678 \mathrm{KW}$ and in the short time horizon 13 hours with a total generation of $5215 \mathrm{KW}$. According to this statistic, the energy cost in the longer time horizon is rise larger than in the shorter time horizon as shown in Fig. 18.

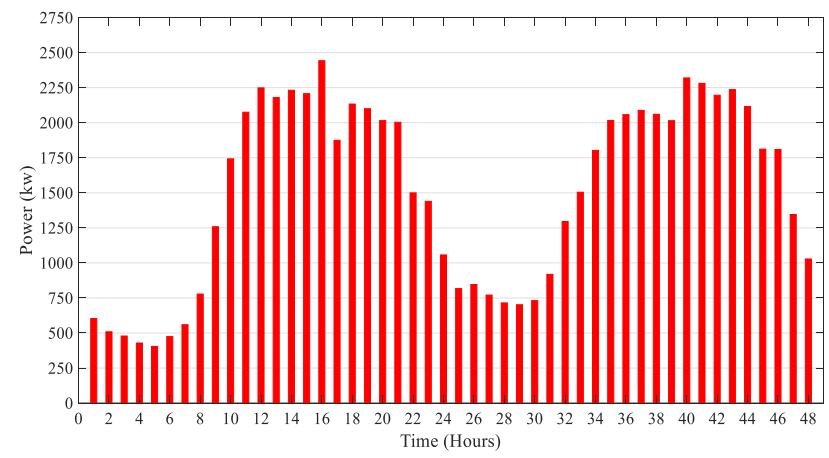

Fig. 14 Demand load profile in the two horizon.

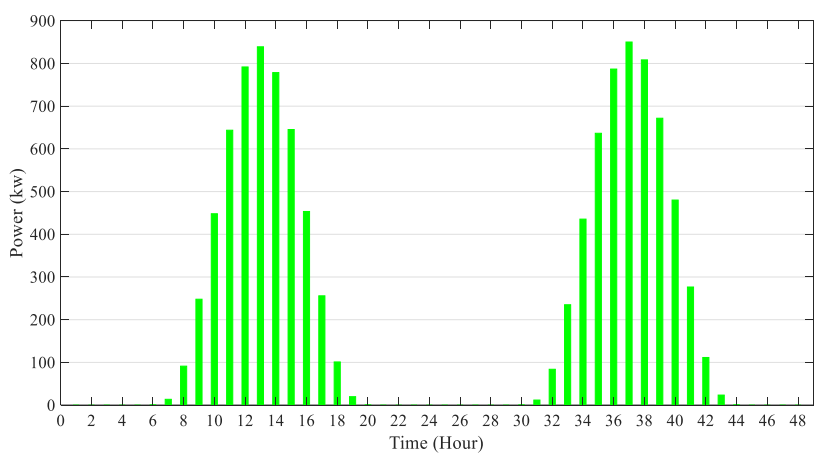

Fig. $15 \mathrm{PV}$ generation profile in the two horizon.

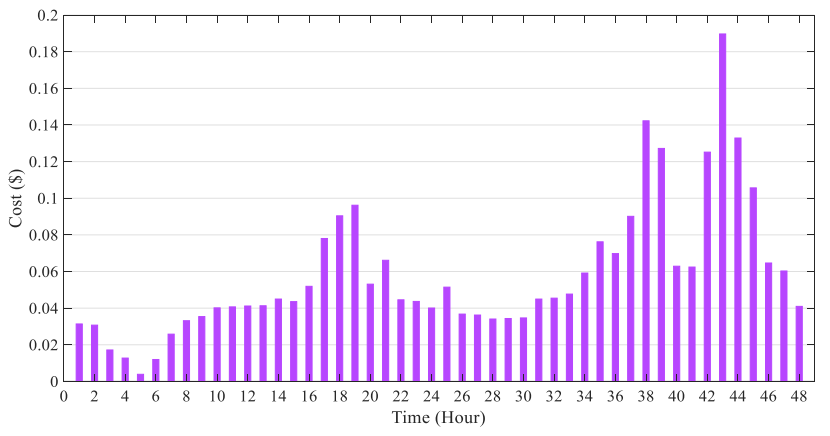

Fig. 16 Energy cost profile in the two horizon.

Table IV contains the details about the amount of consumed fuel in the two horizons. It is clear from the table there is a large difference in fuel consumption between the two horizons, it is noted in the table that the consumed fuel on the long horizon is $3111 \mathrm{~L}$ and in the short horizon is 2342 $\mathrm{L}$ thus the difference is $769 \mathrm{~L}$. This difference makes the average hourly cost high as shown in Fig. 18, where the average in the long horizon is 129 \$ while in the short horizon is $112 \$$. It is noted from the third scenario that the cost of energy and the amount of fuel consumed is higher than if the time horizon is shorter, and the reason for this is the length of the time horizon which affects the forecast of decisions.
The length of the time horizon may affect the optimization results. This impacts the accuracy of decisionmaking and increases the uncertainties of the system, thus increasing fuel expenditures and energy tariffs as shown in the previous section.
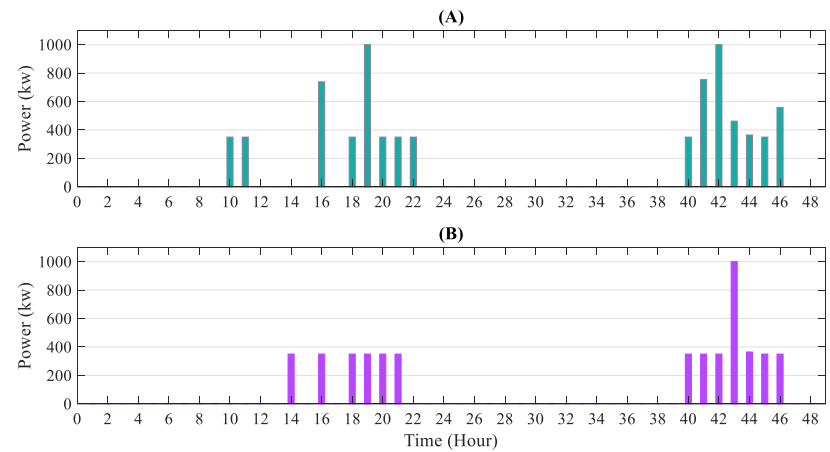

Fig. 17 DG Actions. (A) 48-hour of the two days together, (B) 24-hour horizon of the two days separately.

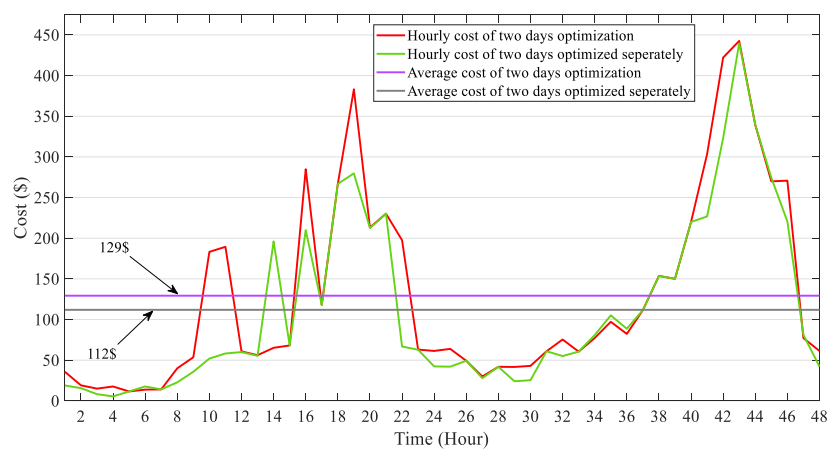

Fig. 18 Hourly energy cost of the two horizon.

To illustrate the superiority of IPSO over PSO, the results of the first scenario has been compared with these obtained using PSO. Fig. 19 shows EMS behavior using the two methods. It is noted from the results that there is less dependence on the utility grid power for the second method, as well as the use of the DG with a higher power than in IPSO, this leads to an increase in the average cost, as is clear in Fig. 20, where the daily total cost using PSO is $2454 \$$ and this cost is relatively large compared to the total cost for the proposed method which is $2129 \$$. Table V shows the energy cost comparison in the case of using the IPSO method or the PSO method.

TABLE IV

Error Ratio of Comparison Factors (48-Hour).

\begin{tabular}{ccc|c}
\hline \hline $\begin{array}{c}\text { Comparison } \\
\text { factor }\end{array}$ & $\begin{array}{c}\text { 48-hour } \\
\text { horizon }\end{array}$ & $\begin{array}{c}\text { 24- hour } \\
\text { horizon }\end{array}$ & $\begin{array}{c}\text { Error } \\
(\%)\end{array}$ \\
\hline \hline $\begin{array}{c}\text { Fuel consumption } \\
(\mathrm{L})\end{array}$ & 3111 & 2342 & $24.7 \%$ \\
\hline $\begin{array}{c}\text { Average daily cost } \\
(\$)\end{array}$ & 6207 & 5373 & $13.4 \%$ \\
\hline $\begin{array}{c}\text { Hourly cost } \\
(\$)\end{array}$ & 129 & 112 & $13.2 \%$ \\
\hline
\end{tabular}


(A)

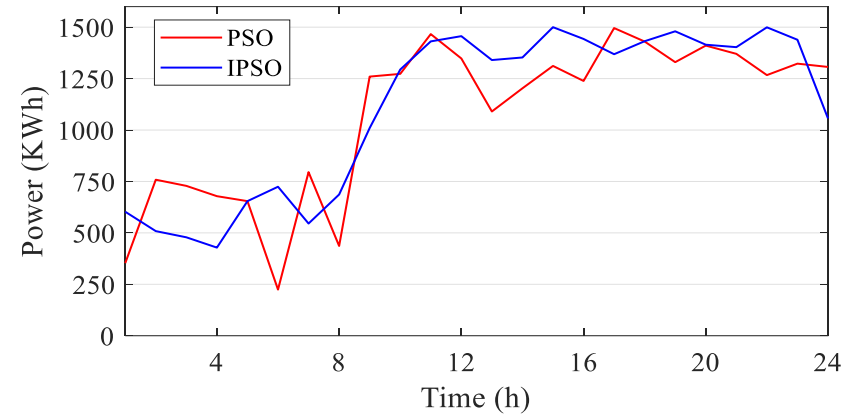

(C)

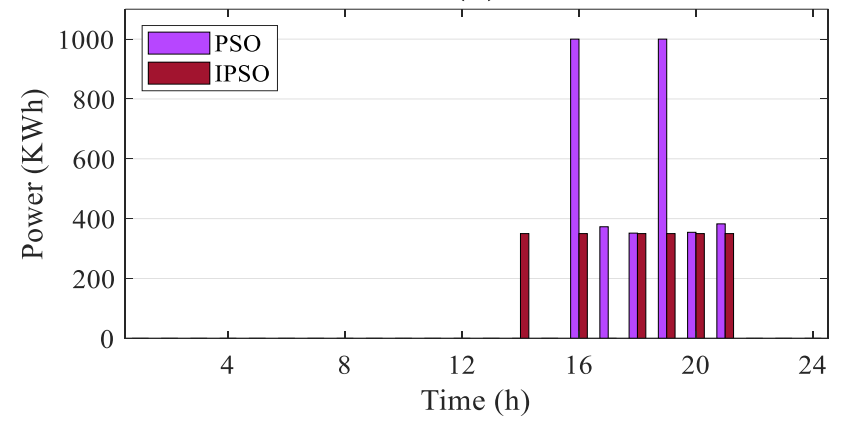

(B)

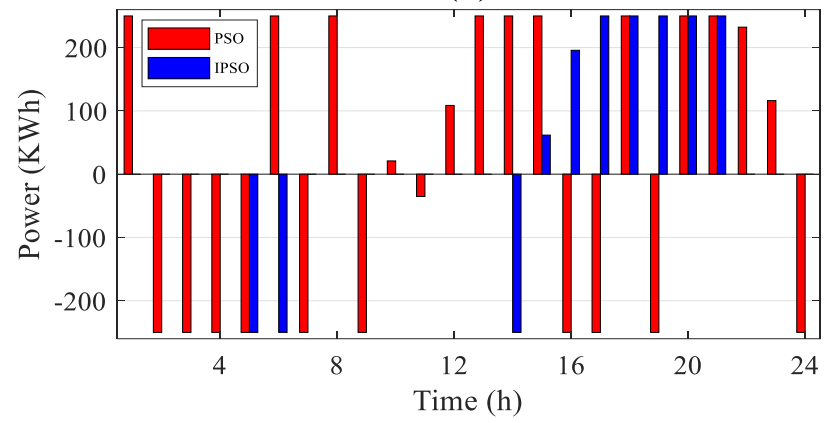

(D)

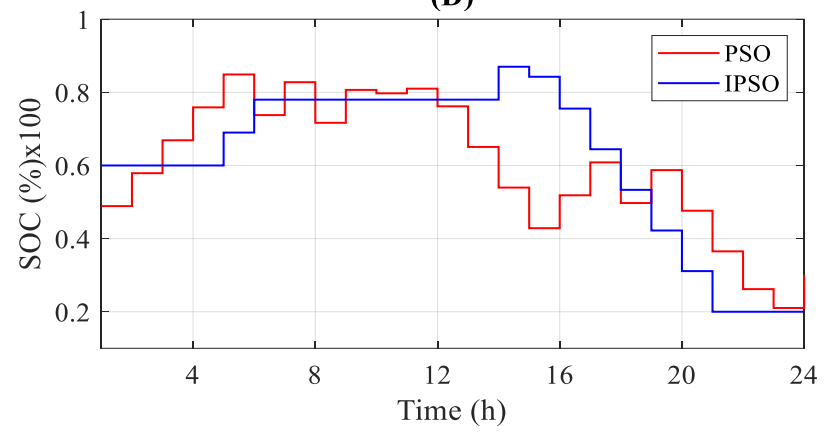

Fig. 19 Comparison between EMS behaviors using IPSO and PSO (A) The utility grid power (B) Battery power (C) DG power (D) SOC.

(A)

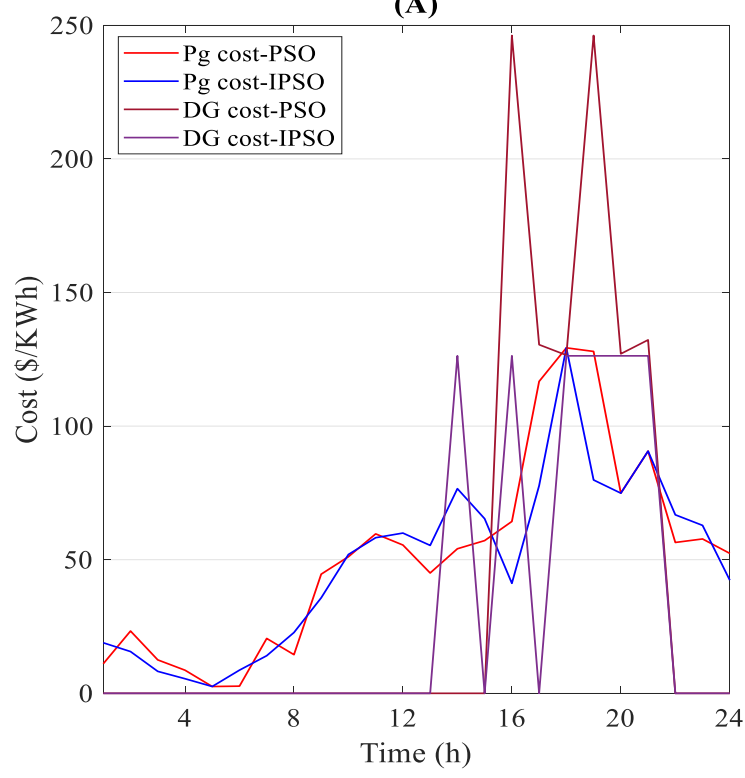

(B)

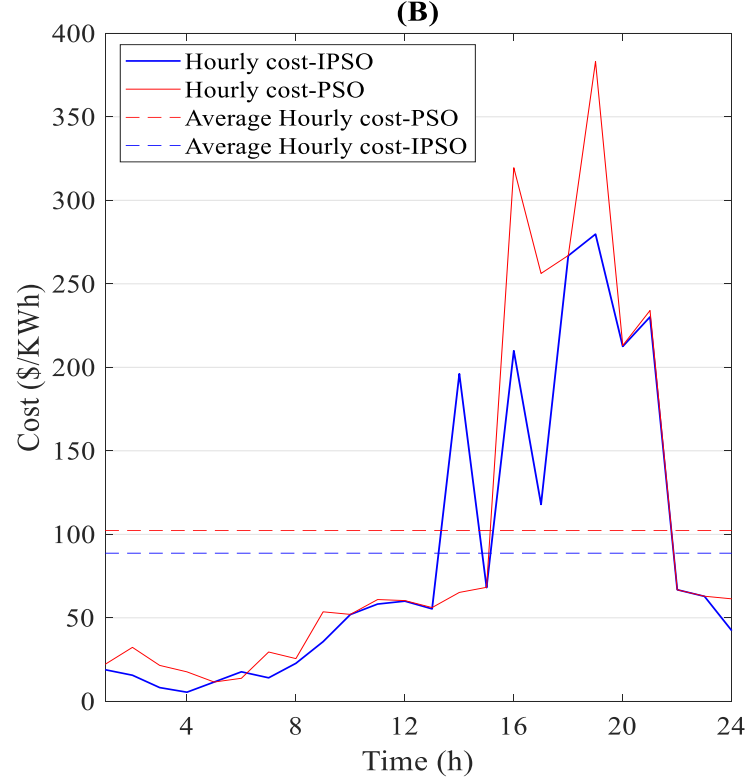

Fig. 19 Energy cost using IPSO and PSO

TABLE V

Energy cost comparison using IPSO and PSO (\$).

\begin{tabular}{ccc}
\hline \hline Energy source & IPSO & PSO \\
\hline Utility grid & 53.22 & 51.4 \\
\hline DG & 31.56 & 42 \\
\hline Battery degradation & 3.92 & 8.85 \\
\hline Total & 88.7 & 102.25 \\
\hline \hline
\end{tabular}

(A) Energy cost of using each resource (B) Hourly cost

\section{CONCLUSIONS}

In this work, it is proposed a day-ahead scheduling technique for DGs in MG consist of the utility grid, DG, PV, and ESS in which the operation is optimized by IPSO to minimize the fuel consumption. The method adopted in this work depends on three scenarios, the first is scheduling using one generator, the second is scheduling using two smaller generators, and the third is suggesting a longer time horizon. It noticed from these scenarios that the second scenario give the best result in term of fuel consumption and energy cost, 
where the DG in the first scenario is forced to run at times to cover a small part of the energy, which represents a small part of the minimum operating limit of DG, and this leads to an increase in energy cost because the cost of energy produced from the DG is considered high due to the high cost of fuel. This problem was overcome in the second scenario by using two DGs with a lower capacity and with a total rate equal to that of the DG used in the first scenario, where it was noted that there is a large difference in fuel consumption, as explained, which results in a lower production cost.

To reduce the times of supplying fuel to the MG from suppliers, it was proposed to increase the time horizon for fuel scheduling by optimizing the operation of energy resources every two consecutive days, which is what was suggested in the third scenario. By comparing the results obtained from the proposed time horizon (48-hour) with the results of the shorter horizon (24-hour), it became clear that there is a significant difference in terms of the number of times the DG is run and the amount of fuel consumption. The reason for this is due to the length of the time horizon, which leads to increased unreliability and the accumulation of data on the optimizer, and this leads to the failure in taking decisions correctly, as was explained in the previous sections. In addition, the results show that the use of the IPSO method is superior to using traditional PSO to optimize the EMS of MG.

\section{CONFLICT OF INTEREST}

The authors have no conflict of relevant interest to this article.

\section{REFERENCES}

[1] F. Katiraei, R. Iravani, N. Hatziargyriou, and A. Dimeas, "Microgrids management," IEEE Power Energy Mag., vol. 6, no. 3, pp. 54-65, May/Jun. 2008.

[2] CERTS Microgrid Concept. [Online]. Available: http://certs.lbl.gov/certs-der-micro.html.

[3] A. G. Madureira and J. A. Pecas Lopes, "Coordinated voltage support in distribution networks with distributed generation and microgrids," IET Renew. Power Gener., vol. 3, no. 4, pp. 439-454, Dec. 2009.

[4] C. Marnay, "Microgrids and heterogeneous power quality and reliability," in Proc. Power Convers. Conf. (PCC), Nagoya, Japan, 2007, pp. 629-634.

[5] Guodong Liu, Yan Xu, and Kevin Tomsovic, "Bidding Strategy for Microgrid in Day-Ahead Market Based on Hybrid Stochastic/Robust Optimization," IEEE Transactions on Smart Grid, Vol. 7, no. 1, pp. 1-11, 2016.

[6] Mofeed Turky Rashid, "Design and Implementation of Smart Electrical Power Meter System", Iraqi Journal for Electrical and Electronic Engineering, Vol. 10, No. 1, pp. 1-14, 2014.

[7] Xin Qiu, Tu A. Nguyen, and Mariesa L. Crow, "Heterogeneous Energy Storage Optimization for Microgrids," IEEE Transactions on Smart Grid, Vol. 7, No. 3, pp. 1453-1461, May 2016.

[8] Liwei Jua, Qinliang Tana, Hongyu Lina, Shufang Meia, Nan Lib, Yan Lud, Yao Wanga, "A Two-Stage Optimal
Coordinated Scheduling Strategy for Micro Energy Grid Integrating Intermittent Renewable Energy Sources Considering Multi-Energy Flexible Conversion," Energy, Vol. 196, 1 April 2020.

[9] A. Sobu and G. Wu, "Dynamic optimal schedule management method for microgrid system considering forecast errors of renewable power generations," in Proc. IEEE Int. Conf. Power Syst. Technol. (POWERCON), Auckland, New Zealand, pp. 1-6, Oct./Nov. 2012.

[10] Zhaoyu Wang, Bokan Chen, Jianhui Wang, Miroslav M. Begovic, and Chen Chen, "Coordinated Energy Management of Networked Microgrids in Distribution Systems," IEEE Transactions on Smart Grid, Vol. 6, No. 1, pp. 45-53, January 2015.

[11] Hongyu Wu, Mohammad Shahidehpour, Zuyi Li, IEEE, and Wei Tian, "Chance-Constrained Day-Ahead Scheduling in Stochastic Power System Operation," IEEE Transactions on Power Systems, Vol. 29, No. 4, pp. 15831591 July 2014.

[12] R. Palma-Behnke et al., "A microgrid energy management system based on the rolling horizon strategy," IEEE Trans. Smart Grid, vol. 4, no. 2, pp. 9961006, Jun. 2013.

[13] H. Morais, P. Kádár, P. Faria, Z. A. Vale, and H. M. Khodr, "Optimal scheduling of a renewable micro-grid in an isolated load area using mixed-integer linear programming," Renew. Energy, vol. 35, no. 1, pp. 151156, Jan. 2010.

[14] Mohammadreza Daneshvar, Behnam Mohammadiivatloo, and Somayeh Asadi, "Optimal Day-Ahead Scheduling of the Renewable Based Energy Hubs Considering Demand Side Energy Management," International Conference on Smart Energy Systems and Technologies (SEST), 2019.

[15] Z. Wu, W. Gu, R. Wang, X. Yuan, and W. Liu, "Economic Optimal Schedule of CHP Microgrid System Using Chance Constrained Programming and Particle Swarm Optimization," IEEE Power and Energy Society General Meeting, 2011.

[16] L. Wu, M. Shahidehpour, and T. Li, "Cost of reliability analysis based on stochastic unit commitment," IEEE Trans. Power Syst., vol. 23, no. 3, pp. 1364-1374, Aug. 2008.

[17] L. Wu, M. Shahidehpour, and T. Li, "Stochastic security-constrained unit commitment," IEEE Trans. Power Syst., vol. 22, no. 2, pp. 800-811, May 2007.

[18] A. Tuohy, P.Meibom, E. Denny, andM. O’Malley, "Unit commitment for systems with significant wind penetration," IEEE Trans. Power Syst., vol. 24, no. 2, pp. 592-601, May 2009.

[19] Fred N. Lee, James Liao, and Art M. Breipohl, "Adaptive Fuel Allocation Using Pseudo Fuel Prices," Transactions on Power Systems, vol. 7, No. 2, pp. 487496, 1992.

[20] S. K. Tong and S. M. Shahidehpour, "An Innovative Approach To Generation Scheduling In Large-Scale Hydro-Thermal Power Systems With Fuel Constrained Units," IEEE Transactions on Power Systems, Vol. 5, No. 2, pp. 665-673, May 1990. 
[21] C. J. Baldwin, K. M. Dale, And R. F. Dittrich, “A Study of the Economic Shutdown or Generating Units in Daily Dispatch," Transactions of the American Institute of Electrical Engineers. Part III: Power Apparatus and Systems, Vol. 78, No. 4, pp. 1272-1282, 1959.

[22] Hans P. Van Meeteren, "Scheduling of Generation and Allocation of Fuel Using Dynamic and Linear Programming," IEEE Power Engineering Review, Vol. PER-4, No. 7, pp. 1562- 1568, July 1984.

[23] T.S. Dillon, K.W. Edwin, H.-D. Kochs, and R.J. Taud, "Integer Programming Approach To The Problem Of Optimal Unit Commitment With Probabilistic Reserve Determination," IEEE Transactions on Power Apparatus and Systems, Vol. PAS-97, No. 6, pp. 2154-2166, Nov/Dec 1978.

[24] Carlos A. Hernandez-Aramburo, Tim C. Green, and Nicolas Mugniot, "Fuel Consumption Minimization of a Microgrid," Ieee Transactions On Industry Applications, Vol. 41, No. 3, pp. 673-681, May/June 2005.

[25] Van-Hai Bui, Akhtar Hussain and Hak-Man Kim, "Double Deep Q-Learning-Based Distributed Operation of Battery Energy Storage System Considering Uncertainties," IEEE Trans. on Smart Grid, Vol. 11, No. $1,2020$.

[26] M. Shahverdi, S.M. Moghaddas-Tafreshi, “Operation Optimization of Fuel Cell Power Plant with New Method in Thermal Recovery Using Particle Swarm Algorithm," in proc. DRPT 2008, pp.2542-2547, April 2008.

[27] Kennedy, J., Eberhart, R., Swarm Intelligence, 1st ed. Massachusetts, USA: Morgan Kaufmann Press, 2009.

[28] Z. Wu, W. Gu, R. Wang, X. Yuan and W. Liu, "Economic Optimal Schedule of CHP Microgrid System Using Chance Constrained Programming and Particle Swarm Optimization," 2011 IEEE Power and Energy Society General Meeting, Conference Paper.

[29] Singiresu S. Rao, "Engineering Optimization Theory and Practice," John Wiley \& Sons, Inc., Fourth Edition, 2009.

[30] W. Liu, P. Zhuang, H. Liang, J. Peng, Z. Huang, "Distributed Economic Dispatch in Microgrids Based on Cooperative Reinforcement Learning," IEEE Trans. Neur Net Learn Syst., vol. 29, pp. 2192-2203, Jun. 2018.

[31] Dennis Michaelson, Hisham Mahmood and Jin Jiang, "Reduction of Forced Outages in Islanded Microgrids by Compensating Model Uncertainties in PV Rating and Battery Capacity," IEEE Power and Energy Technology Systems Journal, Vol. 5, No. 4, 2018.

[32] Mahmoud Elkazaza,b, Mark Sumnera and David Thomasa, "Energy management system for hybrid PVwind-battery microgrid using convex programming, model predictive and rolling horizon predictive control with experimental validation," International Journal of Electrical Power \& Energy Systems Vol. 115, February 2020.

[33] Soumya Mandal, Barun K. Dasa,c and Najmul Hoquea, "Optimum Sizing of a Stand-alone Hybrid Energy System for Rural Electrification in Bangladesh," Vol. 200, pp. 1227, 1 November 2018.

[34] Abdelhamid Kaabeche and Rachid Ibtiouen, "Technoeconomic optimization of hybrid photovoltaic / wind / diesel / battery generation in a stand-alone power system," Vol. 103, pp. 171-182, May 2014.

[35] M.S. Ismail, M. Moghavvemi and T.M.I. Mahlia, "Techno-economic analysis of an optimized photovoltaic and diesel generator hybrid power system for remote houses in a tropical climate," Energy Conversion and Management, Vol. 69, pp. 163-173, May.

[36] Hongbin Wu, Huaidong Zhuang, Wei Zhang and Ming Ding, "Optimal allocation of microgrid considering economic dispatch based on hybrid weighted bilevel planning method and algorithm improvement," Vol. 75, pp. 28-37, February 2016.

[37] Weirong Liu, Peng Zhuang, Hao Liang, Jun Peng and Zhiwu Huang, "Distributed Economic Dispatch in Microgrids Based on Cooperative Reinforcement Learning," IEEE Trans. On Neural Networks and Learning Systems, Vol. 29, Issue 6, pp. 2192-2203, June 2018. 